\title{
The design and implementation of the re-vitalised integrated disease surveillance and response (IDSR) in Uganda, 2013-2016
}

Christine Kihembo ${ }^{1 *}$, Ben Masiira ${ }^{1}$, Lydia Nakiire ${ }^{2}$, Edson Katushabe ${ }^{3}$, Nasan Natseri ${ }^{3}$, Immaculate Nabukenya ${ }^{1}$, Innocent Komakech ${ }^{3}$, Charles Lukoya Okot ${ }^{3}$, Francis Adatu', Issa Makumbi ${ }^{2}$, Miriam Nanyunja ${ }^{3}$, Solomon Fisseha Woldetsadik ${ }^{3}$, Patrick Tusiime ${ }^{4}$, Peter Nsubuga ${ }^{5}$, Ibrahima Soce Fall ${ }^{6}$ and Alemu Wondimagegnehu ${ }^{3}$

\begin{abstract}
Background: Uganda adopted and has been implementing the Integrated Disease Surveillance (IDSR) strategy since 2000. The goal was to build the country's capacity to detect, report promptly, and effectively respond to public health emergencies and priorities. The considerable investment into the program startup realised significant IDSR core performance. However, due to un-sustained funding from the mid-2000s onwards, these achievements were undermined. Following the adoption of the revised World Health Organization guidelines on IDSR, the Uganda Ministry of Health $(\mathrm{MoH})$ in collaboration with key partners decided to revitalise IDSR and operationalise the updated IDSR guidelines in 2012.

Methods: Through the review of both published and unpublished national guidelines, reports and other IDSR program records in addition to an interview of key informants, we describe the design and process of IDSR revitalisation in Uganda, 2013-2016. The program aimed to enhance the districts' capacity to promptly detect, assess and effectively respond to public health emergencies.

Results: Through a cascaded, targeted skill-development training model, 7785 participants were trained in IDSR between 2015 and 2016. Of these, 5489(71\%) were facility-based multi-disciplinary health workers, 1107 (14\%) comprised the district rapid response teams and 1188 (15\%) constituted the district task forces. This training was complemented by other courses for regional teams in addition to the provision of logistics to support IDSR activities. Centrally, IDSR implementation was coordinated and monitored by the MoH's national task force (NTF) on epidemics and emergencies. The NTF and in close collaboration with the WHO Country Office, mobilised resources from various partners and development initiatives. At regional and district levels, the technical and political leadership were mobilised and engaged in monitoring and overseeing program implementation.

Conclusion: The IDSR re-vitalization in Uganda highlights unique features that can be considered by other countries that would wish to strengthen their IDSR programs. Through a coordinated partner response, the program harnessed resources which primarily were not earmarked for IDSR to strengthen the program nation-wide. Engagement of the local district leadership helped promote ownership, foster accountability and sustainability of the program.
\end{abstract}

Keywords: IDSR, Training, Multi-disciplinary, Design, Implementation, Uganda

\footnotetext{
* Correspondence: jckihembo@gmail.com

${ }^{1}$ Epidemiology and Surveillance Division, Ministry of Health, P.O BOX 7072

Kampala, Uganda

Full list of author information is available at the end of the article
}

(c) The Author(s). 2018 Open Access This article is distributed under the terms of the Creative Commons Attribution 4.0 International License (http://creativecommons.org/licenses/by/4.0/), which permits unrestricted use, distribution, and reproduction in any medium, provided you give appropriate credit to the original author(s) and the source, provide a link to the Creative Commons license, and indicate if changes were made. The Creative Commons Public Domain Dedication waiver (http://creativecommons.org/publicdomain/zero/1.0/) applies to the data made available in this article, unless otherwise stated. 


\section{Background}

In 1998, the World Health Organization Africa region (WHO-AFRO) introduced the Integrated Disease Surveillance and Response (IDSR) strategy as one of the approaches to control the disproportionate communicable disease burden in the region [1, 2]. The strategy aimed at strengthening integrated, action-oriented public health surveillance and response at all levels of the health system [3, 4]. In a functional system, all the six IDSR core activities (detection, registration, confirmation, reporting, data analysis and provision of feedback) must operate optimally for prompt public health action $[5,6]$. These are enabled by managerial and support functions such as communication, training, supervision, and resource-provision. Since the introduction of IDSR, 46 member states in WHO-AFRO region have adopted and implemented the strategy to varying levels [7]. Although remarkable improvements in surveillance have been realised in some countries, challenges in IDSR core and support functions still prevail in many of them [8-13]. The strategy, however, has achieved positive outcomes in countries where IDSR support functions such as training, supervision and resource provision were optimal [14]. For example, the number of IDSR trained personnel was found to be directly proportional to improvements in IDSR core function indicators in several WHO-AFRO states [15].

Uganda, like many countries in WHO-AFRO region, is disproportionately affected by endemic, emerging and re-emerging communicable disease burden [16-23]. The rapid population expansion, increased human ecosystem interaction and climate change make the country vulnerable to disease outbreaks [24]. It is imperative that Uganda has a robust public health surveillance and response system that can effectively detect, respond to these public health threats and mitigate their impact [25].

Uganda adopted and has been implementing IDSR since 2000 in a phased manner. Implementation commenced with a baseline assessment of the vertical surveillance programs in the country then a 5-year strategic plan and consequent annual work-plans followed. These aimed at creating a functional early warning surveillance system and appropriate public health response [10]. Subsequently, several initiatives were undertaken to strengthen IDSR in Uganda over the years resulting in evident improvements such as early detection and prompt response to outbreaks [26]. The 2009 assessment of the national public health surveillance systems in the country confirmed these achievements and affirmed that the solid IDSR foundation established could be harnessed to build the WHO/International Health Regulations(IHR 2005) core capacities [27, 28]. This assessment, however, uncovered several challenges affecting IDSR implementation including inconsistent and inadequate support for training, support supervision, communication and feedback. The majority of the districts assessed lacked personnel trained in IDSR. Key reporting tools and reference materials were lacking at the operational level [26, 27].

Following the revision of the generic WHO-IDSR guidelines in 2010, Uganda adopted the changes in revised national IDSR guidelines in 2011. The Ministry of Health $(\mathrm{MOH})$ in collaboration with key partners decided to revitalise the IDSR program and implement the revised guidelines in 2012 (Fig. 1).

The re-vitalisation aimed to enhance the capacity of districts to promptly detect, assess and effectively respond to public health emergencies.

We describe the design and process of IDSR re-vitalisation in Uganda highlighting the roll-out of the revised IDSR guidelines through structured training of the health workforce up to the operational level nation-wide.

\section{Methods \\ Study setting}

The Uganda $\mathrm{MOH}$ is mandated to lead health service delivery including public health emergencies (PHEs), supported by line sectors such as the agriculture and animal industries ministry in the case of zoonotic disease outbreaks [29]. The national task force (NTF) on epidemics and emergencies is a structure under $\mathrm{MOH}$ that coordinates public health emergency response and also is a platform for resource mobilisation, stakeholder engagement and coordination. The NTF reports to the multispectral National Disaster Risk Reduction platform, which platorm ultimately reports to the state cabinet. At the district level, a similar structure, the district task force (DTF) which is an entity of the multisectoral District Disaster Management Technical Committee takes the lead in response to PHEs. Technically, the DTF reports to the NTF [30].

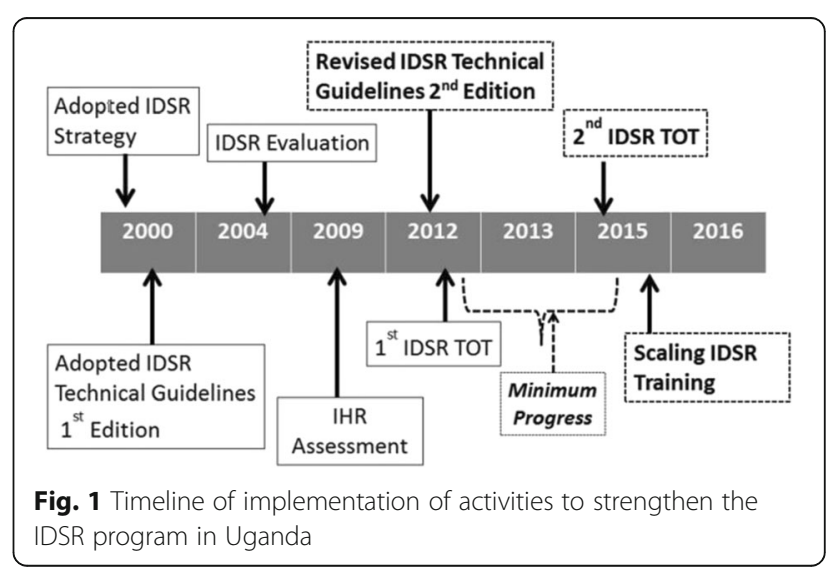


Health service delivery in Uganda is decentralised to districts and health sub-districts (HSD) [31]. By 2015, there were 112 districts within 14 health regions [32]. The health system is structured into national referral hospitals (NRH) at the top, followed by regional referral hospitals (RRHs). These facilities offer a comprehensive health-care including specialised services. General hospitals are at the district level whereas health centre IVs (HCIV) are located at the health sub-districts (HSD) and provide comprehensive services including blood transfusion and comprehensive emergency obstetric care. HCIIIs are found at the sub-county level, are manned by a clinical officer and offer both basic in-patient and out-patient services, whereas HC IIs are at the parish level and provide only out-patient services. The HC I has no physical structure but comprises a village health team(VHT) which links the community to the health system [33]. The district level is the focus for integrating and implementation of IDSR, in addition to health workforce management, support supervision plus health system performance monitoring. The district health department receives reports from HSDs and submits an aggregated report to the national level electronically. The HSD oversees health services within health facilities within the catchment area, receives surveillance reports from these units and submits aggregate data to the district. The District Surveillance Focal Person (DSFP) oversees surveillance activities in the district supervised by the District Health Officer (DHO) [34]. Laboratory or surveillance focal persons at each level ensure safe specimen processing or referral to regional or centralised reference laboratories via the laboratory hub system. Laboratory results are delivered via the reverse mechanism [35].

\section{Study design and procedures}

We reviewed published and unpublished national policy documents and guidelines to document the IDSR implementation framework in Uganda, from 2001 to 2016. We also reviewed preparedness and response protocols developed during the study period, in addition to unpublished reports and minutes of the NTF meeting on epidemics and emergencies. Reports and minutes from the technical working group meetings held for planning and monitoring of the IDSR program during the study period were also reviewed. We reviewed the respective training curriculum documents, training materials, training reports and trainee databases to understand the design, organization and conduct of the training. We also interviewed $18 \mathrm{key}$ informants at the national and district levels to understand the implementation of the training. For information on program funding, we interviewed 10 surveillance focal persons at the districts, $\mathrm{MOH}$ and the WHO Country Office(WCO). We also reviewed the program financial documents including budget documents, procurement and equipment handover records to understand logistics and resources deployed in the process.

\section{The design and development of the nation-wide IDSR training plan}

The 2009 IDSR assessment in Uganda revealed that while substantial resources had been allocated for establishing IDSR in the early to mid-2000s, the marked reduction of funds for IDSR systems over the years led to a loss of previously attained capacities particularly at the operational level [26, 27]. Analysis of the country's responses to disease outbreaks also showed several bottlenecks that needed to be addressed collectively in a coordinated manner. Among them, was a need for a harmonised outbreak response and information flow at the district level.

In 2012, national stakeholders held several NTF meetings to discuss ways of revitalising IDSR in Uganda. They finally reached a consensus about building a competent workforce at the sub-national level to ensure a solid IDSR system. A plan, to implement a nationwide IDSR training to health facilitiesbased on the revised IDSR guidelineswas developed. The training plan was costed at an average cost of US $\$ 230$ per trainee. (Makumbi, I., Personal communication). The training was planned to be accompanied by systematic follow-up visits, regular monitoring and support supervision to improve reliability and quality of the system gradually in a manner that could ensure sustainability and foster accountability. However, between 2013 and 2014, the implementation of the plan stalled mainly due to lack of funding.

\section{Risk of Ebola virus importation from West Africa, a catalyst to IDSR revitalisation}

The Ebola virus disease (EVD) outbreak in West Africa in 2013-2014 posed an imminent risk of importation of the virus to Uganda owing to the many Ugandans supporting the response in West Africa and the unrestricted international travel and trade. $\mathrm{MOH}$ together with partners developed a national EVD/Viral Hemorrhagic Fever (VHF) preparedness and response plan and mobilised resources locally to enhance the country's readiness. Drawing from the lessons of the EVD outbreak in West Africa, and in line with MOH's decision in 2012, this plan prioritised training for frontline health workers to strengthen surveillance and response capacities within the IDSR framework. This training was complemented by building capacity in EVD case management, infection prevention and control (IPC), in addition to the regional capacity for laboratory verification and confirmation (Table 1). 
Table 1 The multi-disciplinary training of health workers conducted to revitalise IDSR in Uganda, 2015-2016

\begin{tabular}{|c|c|c|c|c|c|}
\hline & Type of Training & Level of Training & Target Audience & $\begin{array}{l}\text { Duration } \\
\text { of Training }\end{array}$ & Funder \\
\hline 1 & IDSR Training & District based & $\begin{array}{l}\text { Operational health workers and the } \\
\text { District Health Team (DHT) } \\
\text { District rapid response teams (DRRT): } \\
\text { comprised of DHT and other "one } \\
\text { health" technical personnel; } \\
\text { District Task Force (DTF): The DRRT } \\
\text { plus district technical and political } \\
\text { leadership }\end{array}$ & 5 days & $\begin{array}{l}\text { UK Aid Department for International } \\
\text { Development (DFID) WHO-AFRO, } \\
\text { Polio eradication initiative, Central } \\
\text { Emergency Response Fund, the } \\
\text { Newborn Adolescent and Child } \\
\text { Health (RMANCH) continuum of care, } \\
\text { and USAID through WHO, }\end{array}$ \\
\hline 2 & $\begin{array}{l}\text { Viral Hemorrhagic Fevers } \\
\text { (VHF) case management } \\
\text { and IPC }\end{array}$ & Regional & $\begin{array}{l}\text { Regional teams comprised of mainly } \\
\text { clinicians (doctors, nurses, clinical } \\
\text { officers) and non-clinicians } \\
\text { (hygienists, ambulance drivers, } \\
\text { mortuary attendants, askaris etc). }\end{array}$ & 5 days & DFID, WHO \\
\hline 3 & $\begin{array}{l}\text { Training for laboratory } \\
\text { workers on sample collection, } \\
\text { packaging and transportation } \\
\text { of infectious specimens }\end{array}$ & Regional & $\begin{array}{l}\text { Regional teams comprised of } \\
\text { Laboratory health workers, hub } \\
\text { riders, postal service personnel }\end{array}$ & 5 days & $\begin{array}{l}\text { United States Centres for Diseases } \\
\text { Control and Prevention (CDC) }\end{array}$ \\
\hline 4 & $\begin{array}{l}\text { Other Trainings: District level } \\
\text { epidemiology training } \\
\text { program }\end{array}$ & District based, modular & $\begin{array}{l}\text { District Health Officers, District } \\
\text { Veterinary Officers, District Laboratory } \\
\text { Focal Person, Health sub-district } \\
\text { in-charges }\end{array}$ & 3 month & $\begin{array}{l}\text { Defense Threat Reduction Agency } \\
\text { (DTRA) through the US CDC }\end{array}$ \\
\hline
\end{tabular}

\section{1-District based IDSR training for facility-based health workers, district health team (DHT), district rapid response team (DRRT), and the district task force (DTF)} This training aimed at strengthening the functioning and performance of the national disease surveillance system in addition to enhancing capacity and structures for epidemic preparedness and response at the district level [34]. The expected outcomes of the training were; creation of a critical mass of operational health workers competent in IDSR core activities and support functions, the DRRT competent in outbreak investigation and the DTF competent in epidemic preparedness and response.

Cascade training beginning with the training of national-level trainers (TOT), who then conducted district training was done. Districts were trained in phases starting with high-risk districts (disease outbreak-prone, border districts and those with $<60 \%$ completeness of the weekly epidemiological reporting in the previous quarter).

Based on a customised IDSR training manual, the training content was organised into eight modules to cover surveillance and public health action core activities and support functions (Fig. 2).

Participants covered specific modules relevant to their roles and tasks in IDSR with emphasis on relevant skill development. Training in the form of facilitated workshops with guided practice sessions was held at both national and district levels. Case scenarios generated from real-life events were included to facilitate competence and skill acquisition. Efforts were made to integrate different programs. For-example modules on
m-Trac (a mobile telephone SMS based information system), electronic Health Management and Information System (HMIS), plus tools for maternal and perinatal deaths surveillance were incorporated into the training [36-38]. Participants who had not used the mTrac system were oriented and registered on the platform.

i) Training of health facility-based health workers: From the IDSR core function matrix, IDSR core activities performed at this level are mainly case detection, reporting and data analysis [5, 39]. While these health workers are expected to participate in other IDSR core activities, they are usually supported by the higher levels. Training of operational health workers targeted $80 \%$ coverage of the public sector. These were trained during the first 3 training days, covering modules 1, 2 and 3 (Fig. 2). Additional short modules covered included VHFS' control overview, key strategies and indicators of the national Expanded Programme on Immunisation (EPI), plus the IDSR monitoring framework.

ii) District rapid response team (DRRT) training: A DRRT is a technical, multi-disciplinary team that is responsible for conducting initial outbreak investigation and response within the district. DRRTs were trained on training day 4 covering modules 4 and 8 (Fig. 2). The target was the DHT, the HSD in-charge and DSFP, plus a few staff selected from high priority health facilities

iii) District task force (DTF) training: The DTF is a coordinating committee composed of technical members from various sectors in addition to the 


\begin{tabular}{|c|c|c|c|c|c|c|}
\hline \multirow[b]{2}{*}{ Target Audience } & \multicolumn{5}{|c|}{ Training Days } & \multirow[b]{2}{*}{ Training Modules Covered } \\
\hline & Day1 & Day2 & Day3 & Day4 & Day5 & \\
\hline $\begin{array}{l}\text { Health facility-based } \\
\text { health workers }\end{array}$ & & & & & & \multirow[b]{2}{*}{$\begin{array}{l}\text { Module 1: Identify/detect cases of } \\
\text { priority diseases, conditions and events } \\
\text { Module 2: Report priority diseases, } \\
\text { conditions and events (including SMS } \\
\text { reporting via Mtrack) } \\
\text { Module 3: Analyze and interpret data } \\
\text { Additional short modules: } \\
\text { - VHF: basic epidemiology and control } \\
\text { strategies } \\
\text { - EPI: key approaches, investigations } \\
\text { and indicators } \\
\text { - Key deliverables and IDSR monitoring } \\
\text { framework }\end{array}$} \\
\hline $\begin{array}{l}\text { District Health Team } \\
\text { (DHT) }\end{array}$ & & & & & & \\
\hline $\begin{array}{l}\text { District Rapid } \\
\text { Response Team } \\
\text { (DHT+ technical } \\
\text { personnel from } \\
\text { Health Sub-district } \\
\text { (HSD) and the } \\
\text { veterinary sector) }\end{array}$ & & & & & & $\begin{array}{l}\text { Module 4: investigate suspected } \\
\text { outbreaks and other public health events. } \\
\text { Module 8: Monitor, evaluate and } \\
\text { improve surveillance and response }\end{array}$ \\
\hline $\begin{array}{l}\text { District task force } \\
\text { (DRRT, technical and } \\
\text { political leadership, } \\
\text { key local partners) }\end{array}$ & & & & & & $\begin{array}{l}\text { Module 5: Prepare to respond to } \\
\text { outbreaks and public health events } \\
\text { Module 6: Respond to outbreaks and } \\
\text { public health events } \\
\text { Module 7: Communicate public health } \\
\text { information }\end{array}$ \\
\hline
\end{tabular}

Fig. 2 Structure of the IDSR Training in Uganda, demonstrating module selection and mix for competence and skill development

district political and technical leadership. The DTF's role is to develop and oversee the implementation of emergency preparedness strategies, action plans and procedures [34]. The 1-day DTF training was to enhance district capacity to prepare for and coordinate public health emergency response and this training covered modules 5, 6 and 7(fig. 2). To engage the district leadership to provide oversight of the program, the permanent secretary $\mathrm{MOH}$ issued a circular notice to targeted districts. The letter advocated for a functional disease surveillance and early warning system and pointed out expected key deliverables following IDSR training. This letter was delivered by the central facilitators during a courtesy and mobilisation visit to the district leadership through the DHO prior to the DTF training.

iv) Performance monitoring and accountability framework: A framework for monitoring IDSR performance in the district with key deliverables and indicators was collectively agreed upon during the training. The two indicators selected for monitoring IDSR performance were; the proportion of health facilities submitting weekly surveillance report on time to the district level and the proportion of health facilities conducting a detailed case-based investigation for acute flaccid paralysis and measles cases [34]. Also, the DHT/DTF resolved to include the district's IDSR performance as an agenda item for discussion during all regular health committee meetings. With support from the district leadership, trainers led a detailed discussion of factors that could affect attainment of these indicators and subsequently supported teams to develop tailored action plans to mitigate the issues. Clear next steps and commitments were obtained and followed upon during quarterly support supervision activities and IDSR review meetings.

At the national level, weekly IDSR performance is monitored by both the epidemiology and surveillance/ health information units which provide feedback to the districts through a weekly epidemiology bulletin.

Through the WHO country office, funding for the IDSR training was mobilised from various partners and initiatives including the UK-aid Department for International Development (DFID), WHO-AFRO, the continuum of care for Reproductive Maternal Newborn Adolescent and Child Health (RMANCH), USAID, the Global Polio Eradication Initiative (GPEI) and the Central Emergency Response Fund (CERF) (Table 1).

\section{Regional training on VHF case management and IPC}

This training aimed to build a competent regional team of health workers who could comprehensively manage patients with suspected and confirmed VHFs in the case of an outbreak. The training focused on patient management, IPC, establishment and layout isolation facilities, assembling and operations of mobile teams, safe and dignified burial of VHF victims plus VHF preparedness within the IDSR context. With funding from the DFID through WHO, a national TOT was conducted first and 
cascaded to the regions. The training was based on the national guidelines, and standard operating procedures (SOPS) adapted from the WHO manual for the care and management of patients in Ebola care units [40].

\section{Regional training for laboratory workers on sample collection, packaging and transportation of infectious samples}

To strengthen capacity for laboratory confirmation, laboratory workers were trained on collection and transportation of infectious specimens with support from the US Centres for Disease Control and Prevention under the global health security agenda program. The training aimed at building regional capacity for quality and safe sample referral of infectious specimens within the national laboratory hub network and also targeted staff that interface with specimens via the hub system. The training content included biosafety and biosecurity management principles, bio-risk assessment, IDSR/IHR overview and the role of the laboratory, sample collection and shipment using the International Air Transport Association(IATA) guidelines, the national laboratory hub network operations and laboratory polio control strategies.

\section{Program coordination, harmonisation and oversight}

The coordination of the preparedness and response plan was through the NTF. At MOH, the Director General, Health Services (DGHS) provided technical oversight, supported by technical staff from $\mathrm{MOH}$. The Epidemiology and Surveillance Division, $\mathrm{MOH}$ oversaw direct implementation of the program activities with technical support from WHO Country Office (WCO) and other key partners.

\section{Results}

The initial IDSR TOT was held in 2013 and targeted 30 national trainers. However, the majority of these trainers were deployed to West Africa to support the response to EVD outbreak between 2013 and 2014. Another TOT was conducted in 2015, training 26 participants. National trainers were drawn from the WHO Country Office, $\mathrm{MOH}$ departments and regional referral hospitals and the academia. The regional EPI /IDSR focal persons were prioritised. The pool of national trainers assisted by district trainers enabled concurrent training of multiple districts. Trainers were also identified from DHTs of well-performing districts (districts with consistent weekly HMIS reporting over the previous quarter) to share their best practices and enriched the training.

\section{Rapid scale-up of district-based IDSR training}

Between 2015 and 2016, 7785 participants were trained in IDSR in all the districts in the country by a pool of national and district trainers. Of the 7785 participants trained, 5489 (71\%) were health facility-based health workers, 1107 (14\%) were DRRT members, and 1188 (15\%) constituted the DTF. Among the DTF participants, representatives of key partners and non-governmental organisations within the districts were included.

Health facility-based participants were from various disciplines, including clinicians (nurses, clinical officers and doctors), laboratory staff, HMIS/records and surveillance officers. Participants were drawn from all levels of the health system; 79\% (4337/5489) of the operational health workers were from lower level facilities (HCIIs and HCIIIs), $11 \%$ were from HCIVs and $10 \%$ from the district and regional referral hospitals. All the districts had more than $80 \%$ of the public health facilities represented. High volume private for private health facilities were also included (Table 2).

Review of participant's pre-and post-training assessment scores showed an average knowledge gain of $23 \%$, consistent across all districts (Fig. 3).

In 2015, 488 frontline health workers underwent training on VHF case management and infection prevention and control (IPC). Regional teams comprised 337(69\%) clinicians including doctors, nurses clinical officers and $134(28 \%)$ non-clinicians such as hygienists, ambulance drivers, mortuary attendants and 17(3.5\%) national trainers (Table 3).

Also, 227 participants underwent the laboratory training from eight of the 14 health regions between 2015 and 2016. Participants included 208 (91.8\%) laboratory workers, 4(1.8\%) hub motorcycle riders and 15(6.6\%) postal service personnel. Post-training follow-up and mentorship were provided in an integrated manner. Specifically, within the IDSR/EPI framework, regional focal persons provide technical support supervision to the districts with a special emphasis on IDSR /EPI services on a quarterly basis. Also, by the end of 2016, 30 high-risk districts had had at least one additional support supervision visit from the central team to further consolidate IDSR/HMIS and $\mathrm{m}$-Trac functioning with support from UNICEF.

\section{Other resources, logistics and initiatives deployed to support IDSR/IHR strengthening.}

With support from UNICEF, DFID and WHO-AFRO innovations including $\mathrm{m}$-Trac and e-surveillance were adopted to boost IDSR performance in 2012 [36, 40]. These innovations replaced the traditional cumbersome system for transmitting weekly surveillance and Health Management and Information System (HMIS) data from one health facility level to another physically.

The revised national IDSR/IHR guidelines containing updated surveillance tools and the revised surveillance thresholds booklets were provided as job aides/reference 
Table 2 The distribution of the operational health workers trained during the IDSR revitalization in Uganda, 2015-2016 by level of health facility

\begin{tabular}{|c|c|c|c|c|c|}
\hline \multirow[t]{2}{*}{ Health Region } & \multicolumn{4}{|c|}{ Level of Health Facility Number (\%) } & \multirow{2}{*}{$\begin{array}{l}\text { Time of Training } \\
\text { Month/Year }\end{array}$} \\
\hline & Health Centre II & Health Centre III & Health Centre IV & Hospital & \\
\hline Kampala & $418(46)$ & $288(32)$ & $90(10)$ & $115(13)$ & Jun- 2016 \\
\hline Mbarara & $312(59)$ & $108(20)$ & $72(15)$ & $35(7)$ & Feb- 2016 \\
\hline Masaka & 149 (39) & $140(37)$ & $59(15)$ & $35(9)$ & Dec-2015 \\
\hline Fort Portal & $234(54)$ & $122(28)$ & $50(12)$ & $24(6)$ & Nov-2015 \\
\hline Jinja & $391(56)$ & $198(29)$ & $64(9)$ & $41(6)$ & Nov-2015 \\
\hline Kabale & $93(42)$ & $57(26)$ & $56(25)$ & $15(7)$ & Nov-2015 \\
\hline Mubende & $186(70)$ & $47(18)$ & $15(6)$ & $19(7)$ & Nov-2015 \\
\hline Soroti & $175(45)$ & $119(31)$ & $51(13)$ & $44(11)$ & Nov-2015 \\
\hline Lira & $98(41)$ & $90(38)$ & $43(38)$ & $9(4)$ & Sep-2015 \\
\hline Gulu & $147(48)$ & $100(33)$ & $24(8)$ & $36(12)$ & Jul-2015 \\
\hline Mbale & 137 (35) & $160(41)$ & $34(9)$ & $56(14)$ & Jun-2015 \\
\hline Arua & 107 (29) & $194(53)$ & $34(9)$ & $33(9)$ & May-2015 \\
\hline Hoima & $52(30)$ & $56(32)$ & $31(18)$ & $37(21)$ & May-2015 \\
\hline Moroto & $98(52)$ & $61(32)$ & $7(4)$ & $23(12)$ & May-2015 \\
\hline Total & 2597 (47) & $1740(32)$ & $630(11)$ & $522(10)$ & \\
\hline
\end{tabular}

documents to each participant during IDSR Similarly, national guidelines with standard operating procedures (SOPs) on VHF management and IPC were developed to guide response at various levels of the health system. The national curricula for IDSR and VHF case management courses were developed based on the respective guidelines/SOPs (Table 4).

Due to the lack of isolation units in the country, $\mathrm{MOH}$ with support from DFID through WHO procured five tents, each with a 20-bed capacity designed to serve as emergency isolation facility that can quickly be deployed in case of a VHF outbreak. Assorted drugs, medical supplies and over 2000 sets of personal protective equipment were also procured and pre-positioned at RRHs and district hospitals. The same funding additionally supported the ports of

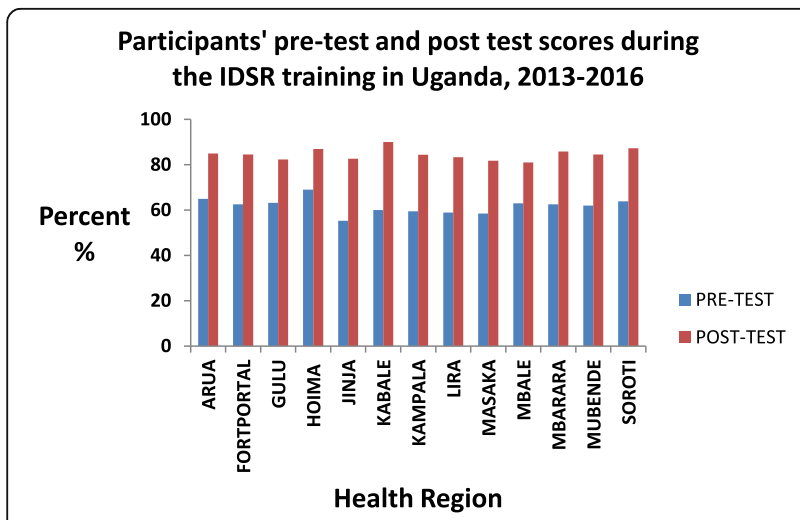

Fig. 3 Participants' pre and post-training assessment scores showing knowledge gain across all health regions during the IDSR training in Uganda 2015-2016
entry(POE) surveillance at the Entebbe International Airport through the acquisition of a walk-through thermal scanner and baseline assessment for IHR capacities at ground POE.

Additionally laboratory supplies including kits and shipment boxes were procured to aid referral of laboratory specimens from districts for prompt diagnosis at the national reference laboratory with financial support from DFID and US Department of Defence. The GPEI and Central Emmergency Response Fund also supported procurement of motorcycles that were provided to strengthen IDSR/EPI surveillance and investigation activities at least 60 high risk districts.

\section{Discussion}

The IDSR revitalisation program in Uganda surpassed the WHO threshold of having trained health workers in IDSR in $\geq 80 \%$ of the districts for effective IDSR performance and achieved nation-wide coverage in 2 years [41]. Significant participant knowledge gain noted across the board was noted across the board, and this was further complemented with post-training support through the integrated support supervision. The number of trained health personnel has been shown to be associated with improvements in IDSR functioning particularly regarding completeness and timeliness of reporting, analysis, interpretation and use of surveillance data at the source $[9,15,42]$. The program also equipped all health workers trained with job aids such as case definitions, surveillance thresholds, reporting forms and national IDSR guidelines. Such tools have been shown to be largely missing at peripheral health system levels in 
Table 3 Categories of health workers trained in VHF case management and IPC plus those trained in safe sample collection and referral in Uganda, 2015-2016

\begin{tabular}{lcc}
\hline Health worker category & Numbers trained (\%) & Time of Training \\
\hline Training on VHF case management and infection prevention and control & $337(69)$ & Sept-Dec 2015 \\
Clinicians & $134(27.5)$ & Sept-Dec 2015 \\
Non-Clinicians & $17(3.5)$ & Jul-2015 \\
National Trainers & $208(91.6)$ & Sep 2015- Aug 2016 \\
Training on sample collection, packaging and transportation of dangerous pathogens for laboratory health workers & $4(1.8)$ & $15(6.6)$ \\
Laboratory workers & & \\
Laboratory hub riders/Transporters & & \\
Postal service personnel &
\end{tabular}

Table 4 Some of the resources and materials deployed to support IDSR/IHR strengthening in Uganda, 2013-2016

\begin{tabular}{|c|c|}
\hline Resource category & Type of resource \\
\hline \multirow{8}{*}{$\begin{array}{l}\text { National curricula, guidelines, } \\
\text { Standard Operating Procedures } \\
\text { (SOPS) and job aids }\end{array}$} & $\begin{array}{l}\text { - National Technical Guidelines for IDSR, } \\
\text { 2nd Edition }\end{array}$ \\
\hline & - National curriculum on IDSR/IHR \\
\hline & $\begin{array}{l}\text { - Case definitions and epidemic thresholds for } \\
\text { IDSR- a working guide for health workers }\end{array}$ \\
\hline & $\begin{array}{l}\text { - Guidelines and SOPS for responding to } \\
\text { Ebola/Marburg virus outbreaks in Uganda }\end{array}$ \\
\hline & $\begin{array}{l}\text { - Curriculum on VHF case management and } \\
\text { infection prevention and control (IPC) }\end{array}$ \\
\hline & $\begin{array}{l}\text { - Updated vaccine-preventable diseases case } \\
\text { investigation forms (Polio/AFP, NNT, } \\
\text { Measles, AEFIs) }\end{array}$ \\
\hline & $\begin{array}{l}\text { - VHT handbook on community-based disease } \\
\text { surveillance. }\end{array}$ \\
\hline & - Curriculum on VHF case management and IPC \\
\hline \multirow[t]{3}{*}{$\begin{array}{l}\text { Contingency medical and laboratory } \\
\text { supplies }\end{array}$} & $\begin{array}{l}\text { - Kits and Shipment boxes for laboratory } \\
\text { specimens }\end{array}$ \\
\hline & $\begin{array}{l}\text { - } 5 \text { tents each with a 20-bed capacity designed to } \\
\text { serve as mobile isolation facilities }\end{array}$ \\
\hline & $\begin{array}{l}\text { - Personal protective equipment (PPE) and } \\
\text { medical supplies }\end{array}$ \\
\hline
\end{tabular}

Other logistical support to strengthen surveillance and IDSR/IHR

MTRACK and Electronic HMIS reporting via DHIS2 System
- A walk through thermoscanner

- Motorcycles and Vehicles

- A short message mobile telephone based reporting platform for weekly HMIS reporting

- Electronic HMIS introduced via the DHIS2 system (open source web-based) introduced

\begin{abstract}
Comments
The revised guidelines were printed and disseminated to participants (Health facility, DHT and DRRT)

National curriculum developed, used for IDSR training

Working guide updated, printed and provided to participants (Health facility, DHT and DRRT)

SOPS and guidelines adapted by a multi-sectoral National Task Force (NTF) team. Printed copies availed at national level

National curriculum adapted and used during VHF case management training
\end{abstract}

Updated case investigation forms disseminated during IDSR training

The training manual was developed

National curriculum adapted

300 laboratory kits supplied

Tents were procured and prepositioned

500 sets of PPEs and assorted medical supplies procured and prepositioned at regional and district hospitals

A walk-through scanner was procured and installed at the international airport to support screening of incoming travellers.

Motorcycles and vehicles procured and given to high-risk districts to support surveillance activities

$m$-trac systems introduced and integrated with the DHIS2 for e-HMIS reporting

${ }^{a}$ AFP Acute Flaccid Paralysis, NNT Neonatal Tetanus, AEFIS Adverse events following immunisation, HMIS Health Management and Information System, DHIS 2 District Health Information Software, DHT District Health Team, DRRT District Rapid Response Team 
many countries, yet are essential to support health workers in executing day today IDSR activities such as reporting $[8,43,44]$.

The design and process of the program implementation also provide valuable and key considerations. Firstly, the IDSR training brought together health workers of multiple disciplines. In higher health facilities, this helped health workers who are primarily not involved in surveillance activities appreciate their indirect yet critical contribution to the program and helped foster teamwork. In lower health units, frontline health workers were identified and equipped with skills to execute relevant IDSR at that level. Training of laboratory staff through the two complementary courses helped supplement the efforts to strengthen laboratory capacity for appropriate pathogen confirmation and sensitivity monitoring, a critical yet one of the weakest program components in the WHO-AFRO region [45-47]. A multi-disciplinary team consisting of the DHT, HSD, and high volume health facilities were trained as the DRRT. This approach was to ensure that competent one health teams that can readily be mobilised and deployed for rapid outbreak investigation and response are available within the districts. Veterinarians at the district level were also included in the DRRT training in the spirit of one health. In contrast to earlier IDSR training where participants covered all eight modules, participants in this training only covered modules that were considered the most crucial to building their required primary skill-set according to the WHO-IDSR function matrix [5]. This approach provided participants adequate time to concretise the content and also shortened the duration participants spent away from duty-stations which is a concern during capacity building initiatives for in-service personnel [15].

Secondly, the cascade approach generated a pool of trainers that enabled concurrent training of multiple districts. Preparations for the training followed a standard checklist, and continuous quality improvement was made based on the end of training evaluation. Districts were engaged to do the selection and mobilisation of participants according to preset criteria. Districts also handled logistical and administrative preparations of the training, an approach that promoted district involvement and ownership of the program. The best practices shared by the district trainers enriched the training and participant action plan development.

Thirdly, the integration of other modules into the IDSR training fostered complementarity of programs, minimising wastage of resources due to duplication of efforts. This was further strengthened by NTF coordination and oversight of the program. Though more elaborate content was covered in the regional VHF and laboratory courses, the training was conducted within the IDSR framework enhancing complementarity.
Fourthly, drawing from lessons learnt during the Ebola outbreak in West Africa, the importance of prompt and effective community engagement in outbreak preparedness and response cannot be underestimated [48-50]. This program approached this component through engagement of the district technical and political leadership to oversee the IDSR implementation and accountability framework. More still, district political leaders in Uganda have free weekly air-time access to advocate, strengthen and monitor government programs through major local media houses in the district. The same platform could be leveraged to further engage and involve the local communities in the IDSR program.

Lastly, the program illustrated how funding from both national programs and partners that otherwise was not directly earmarked for IDSR activities was harnessed to strengthen the program. Lack of sustainable funding of IDSR activities is the major challenge in IDSR implementation in many countries, Uganda inclusive [14]. The program, thus anticipated that funding for IDSR would be incorporated into the districts' budgets, once the program's importance and utility were appreciated by the district leadership. More-still, the WHO /IHR and the CDC global health security agenda advocate for countries to allocate a budget line at the central level to facilitate IDSR implementation which is the vehicle to implement IHR in the region [28].

One limitation in this study is that the key informants' views could have been were influenced by their role in the programme. They could have had a natural bias to focus on positive aspects of the programme and the reviewed records could have forcused on programme successes. However we tried to tease out the pertinent issues and also we triangulated sources of information to mitigate the effect of the limitation.

\section{Conclusion}

The re-vitalisation of the IDSR program in Uganda highlights unique features which can be easily adopted and applied by other countries that would wish to strengthen their IDSR programs. Through a coordinated partner support and response, funding which was not primarily earmarked for IDSR implementation was mobilised and harnessed to achieve nation-wide equipping of multi-disciplinary district teams with skill-sets and tools necessary for performing relevant IDSR functions. The program also promoted engagement of local district leadership which is critical in fostering accountability and is a positive step in exploring sustainability possibility of the program as the long-term funding from governments for global health security is pursued. We demonstrate that when partners work collaboratively and pool their efforts together in a coordinated manner, a significant impact on public health can be achieved countrywide. 


\section{Abbreviations}

AFP: Acute Flaccid Paralysis; CERF: Central Emergency Response Fund; DFID: Department for International Development; DGHS: Director General Health Services; DHIS2: Disrict Health Information Software 2; DHO: District Health Officer; DHT: District Health Team; DRRT: District Rapid Response Team; DSFP: District Surveillance Focal Person; DTF: District Task Force; EPI: Expanded Program on immunization; EVD: Ebola Virus Disease; GPEl: Global Polio Eradication Initiative; HC: Health Centre; HMIS: Health Management and Information System; HSD: Health Sub-district; IATA: International Air Transport Association; IDSR: Integrated Disease Surveillance and Response; IHR: International Health Regulations; IPC: Infection Prevention and Control; MOH: Ministry of Health; NTF: National Task Force on Epidemics and Public HealthEmergencies; PHE: Public Health Emergencies; POE: Port of Entry; RMANCH: for Reproductive Maternal Newborn Adolescent and Child Health; RRH: Regional Referral Hospital; SOPS: Standard Operating Procedures; TOT: Training of Trainers; UK: United Kingdom; UNICEF: United Nations Children's Fund; US CDC: United States Centers for Disease Control and Prevention; USAID: United States Agency for International Development; VHF: Viral Hemorrhagic Fever; VHT: Village Health Team; WCO: World Health Organization Country Office; WHO: World Health Organization; WHO-AFRO: World Health Organization Africa Regional Office

\section{Acknowledgements}

We would like to acknowledge the Epidemiology and Surveillance Division, Ministry of Health Uganda for their support during this study. We also thank the Word Health Organization, Uganda Country Office. Their tireless support in retrieving relevant records and documentation made this work possible. We also would like to thank all the national and district IDSR trainers for the job well done. This study is published with approval from the Ministry of Health Uganda.

\section{Funding}

Funding for the work described in this paper was obtained from various partners and initiatives including the DFID, WHO-AFRO, the continuum of care for Reproductive Maternal Newborn Adolescent and Child Health (RMANCH), USAID, UNICEF, the Global Polio Eradication Initiative and the Central Emergency Response Fund (CERF) through the World Health Organization Country Office for Uganda. The funders however, had no role in the study design, data collection and analysis, decision to publish, or preparation of this manuscript.

\section{Availability of data and materials}

The datasets used and/or analyzed during the current study are available and can be obtained from the corresponding author on reasonable request.

\section{Ethics approval and consent to participate:}

The study was requested by the Uganda Ministry of health. The study protocol was approved by the Uganda national task force on epidemics and PHEs and it was determined not to be human subjects' research. We sought appointments to interview respondents via telephone calls and emails. We provided respondents with information about the study and only interviewed them after obtaining verbal consent. Respondents were informed and assured that their participation was voluntary and their refusal would not result in any negative consequences. Approval to publish this manuscript was obtained from the office of the DGHS, Ministry of Health Uganda through the commissioner, National Disease Control.

\section{Authors contributions}

CK, BM, LN, IM, CLO, FA, PT, SFW, MN, PN and AW contributed significantly to the study conceptualization; IN, ED, NN, IK and FA were instrumental in study data retrieval and acquisition; BM, LN, IN, NN and PN contributed to data analysis; CK analyzed the data and wrote the first draft of the manuscript whereas BM, LN, MN, ISF, PT, PN and AW critically reviewed the manuscript drafts. AW, ISF and PT additionally reviewed the manuscript drafts and gave clearance for publication. All the authors reviewed the manuscript drafts, and approved the final draft.

\section{Consent for publication}

Not applicable.

\section{Competing interests}

The authors declare that they have no competing interests.

\section{Publisher's Note}

Springer Nature remains neutral with regard to jurisdictional claims in published maps and institutional affiliations.

\section{Author details}

${ }^{1}$ Epidemiology and Surveillance Division, Ministry of Health, P.O BOX 7072 Kampala, Uganda. ${ }^{2}$ Public Health Emergency Operations Centre, Ministry of Health, P.O BOX 7072 Kampala, Uganda. ${ }^{3}$ World Health Organization, Uganda Country Office, P.O BOX 24578 Kampala, Uganda. ${ }^{4}$ National Disease Control, Ministry of Health, P.O BOX 7072 Kampala, Uganda. ${ }^{5}$ Global Public Health Solutions LLC, Atlanta, GA 30326, USA. ${ }^{6}$ World Health Organization, Africa Regional Office, Brazzaville, Republic of Congo.

Received: 30 January 2018 Accepted: 26 June 2018

Published online: 13 July 2018

\section{References}

1. WHO-AFRO. Integrated Disease Surveillance Strategy in the African Region: a regional strategy for communicable diseases, 1999-2003. Harare: WHO Regional Office for Africa; 1999.

2. WHO. An integrated approach to communicable disease surveillance. Epidemiol Bull, PAHO. 2000;21:1-16. http://iris.paho.org/xmlui/bitstream/ handle/123456789/31905/EB_v21n1.pdf?sequence=1. Accessed 15 Dec 2017.

3. Nsubuga $P$, White ME, Thacker SB, Anderson MA, Blount SB, Broome CV, Chiller TM, Espitia V, Imtiaz R, Sosin D, et al. Public health surveillance: a tool for targeting and monitoring interventions. In: Jamison JGB DT, Measham AR, Alleyne G, Claeson M, Evans DB, Jha P, Mills A, Musgrove P, editors. Disease Control Priorities in Developing Countries. 2nd ed. New York: The World Bank and the Oxford University Press; 2006.

4. WHO. Overview of the WHO framework for monitoring and evaluating surveillance and response systems for communicable diseases. Wkly Epidemiol Rec. 2004;79(36):322-6.

5. McNabb SJ, Chungong S, Ryan M, Wuhib T, Nsubuga P, Alemu W, CarandeKulis V, Rodier G. Conceptual framework of public health surveillance and action and its application in health sector reform. BMC Public Health. 2002;2(2)

6. CDC: Objectives of Integrated Disease Surveillance and Response (IDSR). In. Atlanta: US CDC; 2012

7. CDC: Assessment of Country-Level Progress for Implementing Integrated Disease Surveillance and Response (IDSR). In: Glob Health-Integrated Disease Surveillance and Response. Atlanta: US Centers for Disease Control and Prevention; 2012.

8. Adokiya Martin N, Awoonor Williams John K, Claudia B, Olaf M. The integrated disease surveillance and response system in northern Ghana: challenges to the core and support functions. BMC Health Serv Res. 2015;15(1):288.

9. Abubakar AA, Sambo MN, Idris SH, Sabitu K, Nguku P. Assessment of integrated disease surveillance and response strategy implementation in selected Local Government Areas of Kaduna state. Ann Nig Med. 2013;7(1):14-9.

10. Nsubuga P, Brown WG, Groseclose SL, Ahadzie L, Talisuna AO, Mmbuji P, Tshimanga M, Midzi S, Wurapa F, Bazeyo W, et al. Implementing integrated disease surveillance and response: four African countries' experience, 1998-2005. Global Public Health. 2010;5(4):364-80.

11. Rumisha SF, Mboera LE, Senkoro KP, Gueye D, Mmbuji P: Monitoring and evaluation of integrated disease surveillance and response in selected districts in Tanzania. Tanzania Health Research Bulletin 2007, 9(1):11-11.

12. Adokiya MN, Awoonor-Williams JK, Barau IY, Beiersmann C, Mueller O. Evaluation of the integrated disease surveillance and response system for infectious diseases control in northern Ghana. BMC Public Health. 2015;15:75. https://doi.org/10.1186/s12889-015-1397-y.

13. Mandyata CB, Kampata L, Mutale W. Challenges of implementing the integrated disease surveillance and response strategy in Zambia: a health worker perspective. BMC Public Health. 2017;17(746, 1)

14. Phalkey RK, Yamamoto S, Awate P, Marx M. Challenges with the implementation of an integrated disease surveillance and response (IDSR) system: systematic review of the lessons learned. Health Policy Plan. 2015;30(1):131-43 
15. Sow I, Alemu W, Nanyunja M, Duale S, Perry HN, Gaturuku P. Trained district health personnel and the performance of integrated disease surveillance in the WHO African region. East Afr J Public Health. 2010;7(1):16-9.

16. Mbonye AK, Wamala JF, Nanyunja M, Opio A, Aceng JR, Makumbi I. Ebola viral hemorrhagic disease outbreak in West Africa- lessons from Uganda. Afr Health Sci. 2014;14(3)

17. Borchert M, Mutyaba I, Van Kerkhove MD, Lutwama J, Luwaga H, Bisoborwa G, Turyagaruka J, Pirard P, Ndayimirije N, Roddy P, et al. Ebola haemorrhagic fever outbreak in Masindi District, Uganda: outbreak description and lessons learned. BMC Infect Dis. 2011;11(1):357.

18. Bwire G, Malimbo M, Maskery B, Kim YE, Mogasale V, Levin A. The burden of cholera in Uganda. PLoS Negl Trop Dis. 2013;7(12):e2545.

19. Kabwama SN, Bulage L, Nsubuga F, Pande G, Oguttu DW, Mafigiri R, Kihembo C, Kwesiga B, Masiira B, Okullo AE, et al. A large and persistent outbreak of typhoid fever caused by consuming contaminated water and street-vended beverages: Kampala, Uganda, January - June 2015. BMC Public Health. 2017;17(1):23.

20. Mafigiri R, Nsubuga F, Ario AR. Risk factors for measles death: Kyegegwa District, western Uganda, February-September 2015. BMC Infect Dis. 2017;17(1):462.

21. Wamala JF, Lukwago L, Malimbo M, Nguku P, Yoti Z, Musenero M, Amone J, Mbabazi W, Nanyunja M, Zaramba S, et al. Ebola hemorrhagic fever associated with novel virus strain, Uganda, 2007-2008. Emerg Infect Dis. 2010;16(7):1087-92.

22. Wamala Joseph F, Mugagga M, Okot Charles L, Atai-Omoruto Ann D, Emmanuel T, Miller Jeffrey R, Stephen B, Trevor S, Charles O, Omony Emmanuel $\mathrm{O}$, et al. Epidemiological and laboratory characterization of a yellow fever outbreak in northern Uganda. Int J Infect Dis. 2011;16(7):e536-42.

23. Bwire G, Mwesawina M, Yosia Baluku SSE, Kanyanda OCG. Cross-border cholera outbreaks in sub-Saharan Africa, the mystery behind the silent illness: what needs to be done? PLoS One. 2016;11(6)

24. Hepworth N, Goulden M. Climate change in Uganda: understanding the implications and appraising the response. In: Scoping mission for DFID-Uganda. Edinburgh: LTS International. p. 2008.

25. Thacker SB, Birkhead GS. Surveillance. In: GM B, editor. Field Epidemiology. 3rd ed. New York: Oxford University Press; 2002. p. 26-50.

26. Lukwago L, Nanyunja M, Ndayimirije N, Wamala J, Malimbo M, Mbabazi W, Gasasira A, Nabukenya IN, Musenero M, Alemu W, et al. The implementation of integrated disease surveillance and response in Uganda: a review of progress and challenges between 2001 and 2007. Health Policy Plan. 2013;28(1):30-40

27. Wamala JF, Okot C, Makumbi I, Natseri N, Kisakye A, Nanyunja M, Bakamutumaho B, Lutwama JJ, Sreedharan R, Xing J, et al. Assessment of core capacities for the international health regulations (IHR2005)-Uganda, 2009. BMC Public Health. 2010;10(Suppl 1):S9.

28. WHO. International health regulations 2005. 2nd ed. Geneva: World Health Organization; 2008.

29. Ministry of Health: Health Sector Development Plan 2015/16-2019/20. In. Edited by Health Mo. Kampala: MOH, September 2015.

30. $\mathrm{MOH}$. National Multi-Hazard Preparedness and Response Plan for Public Health Threats and Emergencies, 2016-2020. Kampala: Ministry of Health Uganda; 2016

31. Anokbonggo WW, et al. Impact of decentralization on health services in Uganda: a look at facility utilization, prescribing and availability of essential drugs. East Afr Med J. 2004;Suppl:S8-11.

32. UBOS. Uganda Demographic and Health Survey 2016: Key Indicators Report. Kampala, Uganda and Rockville, Maryland; Uganda Bureau of Statistics Uganda; 2017.

33. UBOS. National Population and Housing Census 2014- Provisional results. Kampala: Uganda Bureau of Statistics Uganda; 2015.

34. $\mathrm{MOH}$. National Technical Guidelines for Integrated Disease Surveillance and Response. Kampala: Ministry of Health Uganda; 2012.

35. Kiyaga C, Sendagire H, Joseph E, McConnell I, Grosz J, Narayan V, Esiru G, Elyanu P, Akol Z, Kirungi W, et al. Uganda's new National Laboratory Sample Transport System: a successful model for improving access to diagnostic Services for Early Infant HIV diagnosis and other programs. PLoS One. 2013:8(11):e78609.

36. WHO-AFRO. E-Surveillance implementation in the context of Integrated Disease Surveillance and Response in the WHO African Region. In.: WHO Africa Regional Office for Africa; 2015. http://www.afro.who.int/sites/default/files/ 2017-06/esurveillance-implementation-in-the-context-of-integrated-diseasesurveillance-and-response-in-the-who-african-region.pdf. Accessed 9 Jan 2018.
37. mTrac is Changing the Face of Health Operations in Uganda [http://apps. who.int/iris/bitstream/10665/184997/1/WHO_RHR_14.38_eng.pdf].

38. Matthew C. Uganda's experience with real time monitoring: mTrac and U-report. In: SSRN; December. 2012:3.

39. Perry HN, McDonnell SM, Alemu W, Nsubuga P, Chungong S, Otten MW, Lusamba-dikassa PS, Thacker SB. Planning an integrated disease surveillance and response system: a matrix of skills and activities. BMC Med. 2007;5(1):24.

40. World Health Organization: Manual for the care and management of patients in Ebola Care Units/Community Care Centres. In. Geneva,: World Health Organization; January 2015.

41. WHO. Technical review on monitoring and evaluation protocol for communicable disease surveillance and response systems. Geneva, Switzerland 7-9 July 2004. http://www.who.int/csr/resources/publications/surveillance/ Report\%20on\%20ME\%20tech\%20review2.pdf. Accessed 19 Nov 2017.

42. A-NM A-JA. Assessment of the infectious disease surveillance system in Mosul, Iraq. Dohuk Medical Journal. 2008;2:127-38.

43. Gueye DSKP, Rumisha SF. Baseline Monitoring and Evaluation of Integrated Disease Surveillance and Response in Tanzania. Bethesda: PhRplus and USAID; 2005.

44. Pond BESH, Wamala J, Lukwago L. Mid-Term Evaluation of the Integrated Disease Surveillance and Response Project. Washington DC: USAID and Management Systems International; 2011.

45. Masanza MM, Nqobile N, Mukanga D, Gitta SN. Laboratory capacity building for the international health regulations (IHR[2005]) in resource-poor countries: the experience of the African field epidemiology network (AFENET). BMC Public Health. 2010;10(1):S8.

46. Muula A, Maseko F. Medical laboratory services in Africa deserve more. Clin Infect Dis. 2006:42(10)

47. Onyebujoh PC, Thirumala AK, Ndihokubwayo J-B. Integrating laboratory networks, surveillance systems and public health institutes in Africa, vol. 5; 2016.

48. Gillespie AM, Obregon R, El Asawi R, Richey C, Manoncourt E, Joshi K, Naqvi S, Pouye A, Safi N, Chitnis K, et al. Social mobilization and community engagement central to the Ebola response in West Africa: lessons for future public health emergencies. Global Health: Science and Practice. 2016;4(4):626-46.

49. Li Z-J, Tu W-X, Wang X-C, Shi G-Q, Yin Z-D, Su H-J, Shen T, Zhang D-P, Li J-D, Lv S, et al. A practical community-based response strategy to interrupt Ebola transmission in sierra Leone, 2014-2015. Infect Dis Poverty. 2016;5(1):74.

50. WHO: A guide for establishing community based surveillance. In: Integrated Disease Surveillance and Response in the African Region Disease Surveillance and Response programme Area Congo Brazzaville: World Health Organisation Disease Control and Prevention Cluster WHO Africa Regional Office; 2014.

\section{Ready to submit your research? Choose BMC and benefit from:}

- fast, convenient online submission

- thorough peer review by experienced researchers in your field

- rapid publication on acceptance

- support for research data, including large and complex data types

- gold Open Access which fosters wider collaboration and increased citations

- maximum visibility for your research: over $100 \mathrm{M}$ website views per year

At BMC, research is always in progress.

Learn more biomedcentral.com/submissions 